\title{
APLICAÇÃO DA TOXINA BOTULÍNICA NA TERAPÊUTICA DA ENXAQUECA
}

\author{
APPLICATION OF BOTULINUM TOXIN IN MIGRAINE THERAPY
}

\author{
Ana Paula Freitas ${ }^{1}$ \\ Gabriel Ferreira ${ }^{2}$ \\ Luana Andrade Batista ${ }^{3}$ \\ Mariana Gomes Oliveira ${ }^{4}$ \\ Nelicy Fernandes Firmino ${ }^{5}$ \\ Thalita Dias Rocha Lara ${ }^{6}$ \\ Vanessa Marques dos Passos ${ }^{7}$ \\ Mirian Cristina de Oliveira ${ }^{8}$
}

RESUMO: A proteína produzida pela bactéria Clostridium botulinum é chamada de toxina botulínica, que após ser ingerida em altas quantidades impede os sinais nervosos do cérebro para a musculatura causando uma paralisia generalizada que se denomina botulismo. Apesar disso, quando quantidades pequenas são injetadas na musculatura facial específica, apenas o impulso que o orienta será bloqueado, causando o relaxamento do local, podendo ser utilizada em procedimentos estéticos e também de forma terapêutica como exemplo para tratar enxaqueca que é um transtorno do Sistema Nervoso Central que vem associada a dor e náuseas. Os pacientes que sofrem com essa síndrome geralmente utilizam analgésicos para alivio rápido da dor, porém a casos tão graves que os pacientes precisam procurar apoio médico. A toxina vai agir de forma que o paciente não tenha os estímulos para o aparecimento das crises e também tem a função de ajudar a liberar substâncias analgésicas para alivio da dor. O tratamento tem trazido bons resultados aos pacientes tem tido redução na intensidade e frequência dos episódios de dor.

Palavras-chave: Toxina botulínica. Enxaqueca. Clostridium botulinum.

ABSTRACT: The protein produced by the bacterium Clostridium botulinum is called botulinum toxin, which after being ingested in high amounts blocks nerve signals from the brain to the musculature, causing a generalized paralysis called botulism. However, when small amounts are injected into the specific facial musculature, only the impulse that guides

\footnotetext{
'Discente do curso de Biomedicina da Faculdade Única de Ipatinga.

${ }^{2}$ Discente do curso de Biomedicina da Faculdade Única de Ipatinga.

${ }^{3}$ Discente do curso de Biomedicina da Faculdade Única de Ipatinga.

4Discente do curso de Biomedicina da Faculdade Única de Ipatinga.

${ }^{5}$ Discente do curso de Biomedicina da Faculdade Única de Ipatinga.

${ }^{6}$ Discente do curso de Biomedicina da Faculdade Única de Ipatinga.

7Discente do curso de Biomedicina da Faculdade Única de Ipatinga

${ }^{8}$ Orientadora. Mestra. Docente do curso de Biomedicina da Faculdade Única de Ipatinga.
} 
it will be blocked, causing the site to relax, and it can be used in aesthetic procedures and also therapeutically as an example to treat migraine, which is a System disorder Central nervous which is associated with pain and nausea. Patients suffering from this syndrome usually use analgesics for quick pain relief, but in cases so severe that patients need to seek medical support. The toxin will act so that the patient does not have the stimuli for the onset of crises and also has the function of helping to release analgesic substances to relieve pain. The treatment has brought good results to patients and there has been a reduction in the intensity and frequency of pain episodes.

Keywords: Botulinum toxin. Migraine. Clostridium botulinum.

\section{INTRODUÇÃO}

Devido ao alto predomínio de casos, a enxaqueca se torna um problema de saúde pública, que pode atrapalhar muitas atividades do cotidiano. É caracterizada por dores na metade da cabeça e podem ter associação com outros sintomas. (STEFANE et al, 2012).

Sabe-se que a toxina botulínica está sendo usada em diversos procedimentos estéticos atualmente, mas o BOTOX ainda precisa de visibilidade das vantagens terapêuticas. A intervenção terapêutica com a toxina botulínica na profilaxia de enxaquecas tem trago resultados eficazes e seguros. Constitui-se no método de aplicação intramuscular em torno de 3I pontos determinados que promove a inibição do ciclo de dor. (TAVARES, 2017).

Esse estudo tem como objetivo, expor as vantagens da toxina botulínica no tratamento de enxaqueca como uma alternativa segura, a fim de minimizar a escolha de tratamento profilático medicamentoso.

\section{METODOLOGIA}

Para o presente estudo foram lidas e analisadas pesquisas de artigos sobre o assunto abordado. O trabalho foi escrito com fundamentos de artigos, trabalhos acadêmicos, sites confiáveis, entre outros. Esses meios de pesquisas foram usados para debate do grupo na definição e elaboração desse trabalho. Dessa forma, o trabalho seguirá utilizando conceitos e ideias de outros autores como referência. $O$ tema tratado no estudo engloba muitas disciplinas do curso de biomedicina tanto cursadas como em curso dentre elas temos a Neuroanatomia, Patologia Humana, Bioquímica, Fisiologia humana e microbiologia.

Os sites de busca para a realização do trabalho foram voltados para trabalhos publicados em revistas científicas com versões online. As palavras-chave utilizadas para busca desse material e desenvolvimento da revisão foram 'toxina botulínica', 'enxaqueca', 
'mecanismo' e 'ação' da toxina botulínica. Foram utilizados 13 artigos de referência científica contendo datas entre 2004 a 2018 para a construção de todo o trabalho, observando o ano de publicação dos artigos para a conclusão do presente artigo

\section{DESENVOLVIMENTO}

\section{I Cefaleia E Enxaqueca}

As cefaleias são dores em qualquer parte da cabeça como na face, couro cabeludo, pescoço, e o interior da cabeça. Apesar das variações de cada região, cefaleia é um problema de distribuição mundial, que não tem restrição de pessoas. Acomete todas as idades, raças e nível econômico, em algum momento da vida sentiremos dores de cabeça. (STEFANE et al., 2012).

Já a enxaqueca é classificada como uma enfermidade neurovascular crônica determinado pela inflamação neurogênica com mudança no sistema serotoninérgico (fundamental para o desenvolvimento do sistema nervoso) e apresentando vasodilatação das artérias situadas nas meninges, responsáveis pelo principal sintoma que é a dor.

(MENEZES et al, 2007). As dores de cabeça são consideradas severas e frequentemente associadas a ocorrências como sensibilidade a luz, náuseas, vômitos e sons no momento da crise (BLUMENFELD et al, 2004).

Segundo com as informações do ministério da saúde no Brasil, pesquisas mostram que cerca de 30 milhões de indivíduos apresentam a enxaqueca, sendo $5 \%$ a $25 \%$ são mulheres e 2\% a I0\% são homens. A faixa etária mais afetada está entre 25 a 45 anos, e observa-se uma tendência na queda das crises após os 50 anos, nas crianças ocorrem de $3 \%$ a $10 \%$ independente do sexo antes da puberdade. (PAHIM, et al. 2006).

\subsection{O surgimento da toxina botulínica e sua forma de agir}

Clostridium botulinum são bactérias anaeróbicas que foram isolados pela primeira vez pela bacteriologista da Universidade de Ghent, Emile Pierre-Marie van Ermengem, em meados de 1895. (WHITCUP SM et al., 2014). Sabemos que existem muitos subtipos de toxinas botulínicas, todavia, são observadas apenas sete sorotipos de acordo com as características do antígeno presente em cada um deles, designados A, B, C, D, E, F, G; quaisquer desses sorotipos atuam impedindo a liberação da acetilcolina, mas a toxina 
botulínica do tipo A é a mais estudada e por isso a mais utilizada no tratamento da enxaqueca (PARK e PARK, 2017).

O BOTOX tem sido estudado para a administração profilática de diversas doenças, com o intuito de evitar uso de medicamentos e reações adversas do mesmo. (ARAUJO, 2018). A iniciação da atuação da toxina no músculo acontece entre 2 a 5 dias se prolongando até duas semanas. A durabilidade média do resultado da toxina é de 4 meses. (KREUTZ, 20II). A toxina botulínica age no enfraquecimento da musculatura dolorosa, com isso é estabelecido uma diminuição da dor e não apenas na área dos resultados neuromusculares, sugerindo que tenha ação direta sobre a dor (ROBERTSON; GARZA, 20I2).

A aplicação terapêutica da toxina botulínica foi consentida pela FDA (Food and Drug Administration) em 1957 como uma opção segura e eficaz. Portanto, para se utilizar a toxina botulínica do tipo A é necessário a purificação da toxina de acordo com a FDA. Hoje, essa toxina é comercializada na forma e com o nome de BOTOX. Observa-se no Quadro I os critérios de acordo com a FDA para a obtenção da toxina botulínica tipo I cristalina purificada. (SPOSITO, 2004).

Quadro I - Método de qualidade para obter BoNT/A

1 Produção de 12-16 litros de cultura contendo caseina hidrolizada, extrato de levedura e dextrose (sem alimentos de origem animal), em pH de 7,3 com a cepa Hall do C.

Botulinum tipo $\mathrm{A}$, que tenha um rendimento de $10^{11} \mathrm{MDL}_{50}$ por $\mathrm{ml}$.

2 Purificação realizada por método que não exponha a toxina a resinas sintéticas, solventes ou substâncias antigênicas que possam ser carregadas, mesmo que em traços, para a molécula final da toxina cristalina.

3 Deve apresentar máxima absorbância (capacidade de migração) de 278mm, com uma variação entre 260-278 / 0.6 ou menos.

4 Deve apresentar toxicidade especifica de $3 \pm 20 \% \times 10^{12} \mathrm{MDL}_{50}$ por $\mathrm{mg}$

5 Teste analitico do material deve ser feito através de eletroforese em gel.

Legenda: BoNT/A = botulinum neurotoxin type $A$

Fonte: Sposito, 2004 
A toxina botulínica é formada, por um agrupamento de proteínas que contém neurotoxinas com 150.000 Daltons e proteínas que auxiliam a não toxicidade, conservação e proteção do princípio ativo, esse agrupamento resulta em um peso molecular que pode variar de 300.000 a 900.000 Daltons, modificando de acordo com o sorotipo e da cepa ou subespécie de Clostridium botulinum, e também conforme a técnica utilizada para purificar e analisar a toxina. Em condições metabólicas é esperado que o agrupamento proteico seja dissociado e libere a neurotoxina pura, pois os grupamentos possuem estabilidade apenas em um $\mathrm{pH}$ ácido, essa separação inicial entre a cadeia leve e a pesada é o marco categórico para ativação da toxina, a quantidade de separação inicial das cadeias, depende do sorotipo da toxina, sendo a toxina do sorotipo A, com maior separação (90 a 95\%). Após a separação inicial, a cadeia leve é transferida por meio da membrana da vesícula endocítica para o dentro da matriz citoplasmática e se conecta ao receptor SNARE (proteínas responsáveis na liberação dos neurotransmissores) que detém a exocitose de neurotransmissores. A toxina botulínica tem uma cadeia de proteína leve e uma cadeia pesada que estão conectadas pela ligação covalente, do tipo ponte dissulfeto. A cadeia pesada é encarregada pela interiorização da toxina nos terminais colinérgicos pré-sinápticos, já a cadeia leve é encarregada pelo efeito da toxina. A toxina é uma protease encarregada pela separação inicial dos receptores SNARE, que é o pilar para ação da toxina sobre a liberação dos neurotransmissores. (COLHADO, et al. 2009).

\subsection{Como a toxina botulínica age na dor}

O efeito da Toxina botulínica nos casos de cefaleia ainda não é bem entendido (ROBERTSON; GARZA, 2012). Foi provado que a toxina botulínica tem o poder de conseguir diminuir a força da musculatura dolorosa sendo possível o alivio da dor. Observou-se, que os benefícios na dor não correspondiam apenas à região dos efeitos neuromusculares. As pesquisas nos mostram que os efeitos provocados pela toxina no alívio da dor provêm de interação com os tecidos periféricos e ações sob o mecanismo central da dor, um desempenho mais complexo que apenas relaxamento muscular (COLHADO, et al. 2009).

A aplicação da toxina botulínica A afeta diretamente o mecanismo de ação das junções neuromusculares. Ela entra nos terminais nervosos através de endocitose, que reage com as proteínas intracelulares (proteínas SNARE) gerando uma paralização na liberação 
de acetilcolina dos terminais nervosos, tudo isso sem prejudicar a condução de sinais elétricos ou a síntese e armazenamento de acetilcolina. Esse sistema de inibição causa um processo de desenervação química e a paralisia dos músculos estriados. O pico de paralisação ocorre após 2 semanas da aplicação da toxina, e a atividade neuronal tende a retornar após 3 meses e a sua função completa em torno de 6 meses. (BLUMENFELD, et al. 2004).

Apesar de a inibição neuromuscular aliviar parte da dor associada com a dor de cabeça, não é possível explicar totalmente o mecanismo de alívio da dor mediada pela toxina., Pesquisas intensivas sobre a toxina botulínica tipo A sugerem que a toxina pode exercer interação com outras vias de sinalização neuronal, apesar de que os mecanismos exatos permaneçam ainda desconhecidos. Os dados atuais sugerem que a toxina botulínica A modifica a resposta sensorial do sistema nervoso central bloqueando as fibras situadas no interior do fuso muscular resultando na diminuição da ativação dos fusos musculares. Isso altera efetivamente o sistema sensorial das vias aferentes (estrutura responsável por levar os impulsos nervosos até o sistema nervoso central). (BLUMENFELD, et al. 2004).

\section{CONSIDERAÇÕES FINAIS}

A toxina botulínica apresenta um desenvolvimento considerável como um proposito terapêutico, essencialmente nas doenças que se caracterizam por uma contração muscular excessiva como a enxaqueca. É importante que sejam seguidos com atenção a dosagem correta e os intervalos entre as aplicações para que os efeitos da toxina não sejam diminuídos, lembrando que a administração da toxina tem que ser realizada por um profissional qualificado. Para eficácia da toxina com mecanismo do alivio da dor, será essencial pesquisas futuras para estabelecer.

\section{REFERÊNCIAS BIBLIOGRÁFICAS}

ARAÚJO, Lara. O uso da toxina botulínica no tratamento da enxaqueca. UniCEUB Brasília, p. 1-27, Abril 2017. Acesso em: 22 set. 2021.

BLUMENFELD, Andrew M.; DODICK, David W.; SILBERSTEIN, Stephen D. Botulinum neurotoxin for the treatment of migraine and other primary headache disorders. Dermatologic clinics, v. 22, n. 2, p. 167-175, 2004. Acesso em is de abril de 2021. 
COLHADO, Orlando; BOEING, Marcelo; ORTEGA, Luciano. Botulinum Toxin in Pain TreatmentToxina Botulínica no Tratamento da DorToxina Botulínica en el

Tratamiento del dolor. Brazilian Journal of Anesthesiology, [s. l.], May-june 2009.. Acesso em: I4 set. 202I.

KREUTZ, L. M. O uso da toxina botulínica tipo A na profilaxia da enxaqueca, 20II. 34f. Trabalho de Conclusão do Curso de Farmácia da Universidade Federal do Rio Grande do Sul, Porto Alegre, 2orr.

MENEZES, Carla et al. Botulinum toxin type A in refractory chronic migraine: an openlabel trial. Arquivos de neuro-psiquiatria, v. 65, n. 3A, p. 596-598, 2007. Disponível em: Acesso em 26 de abril de 2021.

PAHIM, Luciane Scherer; MENEZES, Ana M B; LIMA, Rosângela. Prevalência e fatores associados à enxaqueca na população adulta de Pelotas, RS. Revista de Saúde Pública, [S.L.], v. 40, n. 4, p. 692-698, ago. 2006. FapUNIFESP (SciELO).

PARK, JungHyun; PARK, Hue Jung. Botulinum toxin for the treatment of neuropathic pain. Toxins, v. 9, n. 9, p. 260, 2017. Disponível em: Acesso em 20 de abril de 2021.

ROBERTSON, C. E.; GARZA, I. Critical analysis of the use of onabotulinumtoxinA (botulinum toxin type A) in migraine. Neuropsychiatric Disease And Treatment, USA, p. 35-48, jan., 2012.

SPOSITO, Maria. Toxina botulínica tipo A - propriedades farmacológicas e uso clínico. ACTA FISIÁTRICA, p. I-40. 2004. Acesso em 24 de setembro de 202I.

STEFANE, Thais et al. Influência de tratamentos para enxaqueca na qualidade de vida: revisão integrativa de literatura. Revista Brasileira de Enfermagem, Brasilia, 24 jan. 2012. Acesso em: 22 set. 2021.

TAVARES, Francisca. A TOXINA BOTULÍNICA NO TRATAMENTO DA ENXAQUECA CRÓNICA: Dissertação de Mestrado Integrado em Medicina. Instituto de Ciências Biomédicas Abel Salazar, Porto, 2017.. Acesso em: 22 set. 2021. 
WHITCUO SM, Turkel CC, DeGryse RE, Brin MF. Development of onabotulinumtoxinA for chronic migraine. Ann N Y Acad Sci. 2014;1329:67-80.

World Health Organization (WHO). Fact sheet: headache disorders. Genebra, 2or6. Acesso em: 5 jul de 2016. 